Boise State University

ScholarWorks

Anthropology Faculty Publications and

Presentations

Department of Anthropology

$4-2016$

\title{
The Effects of Wealth on Male Reproduction Among \\ Monogamous Hunter-Fisher-Trappers in Northern Siberia
}

John P. Ziker

Boise State University

David A. Nolin

University of Missouri

Joellie Rasmussen

Clearwater Analytics

This document was originally published in Current Anthropology by the University of Chicago Press. Copyright restrictions may apply. doi: 10.1086/685730 


\section{Reports}

\section{The Effects of Wealth on Male Reproduction among Monogamous Hunter- Fisher-Trappers in Northern Siberia}

\section{John P. Ziker, David A. Nolin, and Joellie Rasmussen}

Department of Anthropology, Boise State University, 1910 University Drive, Boise, Idaho 83725, USA (jziker@boisestate .edu)/Department of Anthropology and Life Sciences and Society Program, University of Missouri, Columbia, Missouri 65211, USA/Joellie Rasmussen, Clearwater Analytics, 950 West Bannock Street, Suite 1050, Boise, Idaho 83702, USA. This paper was submitted 13 II 15, accepted 7 IV 15, and electronically published 9 III 16.

CA + Online-Only Material: Supplement A

Variability in men's reproductive success (RS) is partly attributable to the ability of successful men to influence resource flows relevant to the mate choice and reproduction of women. This study explores the effects of variability in resource flows on men's RS in an indigenous foraging/mixed-economy community in northern Siberia where monogamous marriage norms predominate. A series of material, embodied, and relational wealth indicators are tested as predictors of men's age-adjusted RS and age at first birth. Material wealth related to hunting, embodied wealth as represented by hunting skill, and relational wealth as represented by numbers of kin are the most consistent predictors of men's RS. In this monogamous population, the wives of men with more hunting capital and of men rated as better hunters have shorter interbirth intervals, and hunters show strong producer priority. These findings and ethnographic observations appear more consistent with a provisioning model than with a signaling-formates model.

Across human populations, a man's ability to procure, secure, control, or draw upon resources has been shown to influence his reproductive success (RS; Nettle and Pollet 2008). Variability in men's RS has been shown to vary with military prowess (Chagnon 1979, 1988), political power (Hill and Hurtado 1996; Betzig 1997), economic success (Irons 1979), hunting ability (Smith 2004), alloparenting (Hill and Hurtado 1996; Sear and Mace 2008), and wealth (Borgerhoff Mulder and Beheim 2011; von Rueden et al. 2011). Initial

(C) 2016 by The Wenner-Gren Foundation for Anthropological Research. All rights reserved. 0011-3204/2016/5702-0007\$10.00. DOI: 10.1086 1685730 studies of the relationship between wealth or status and fertility in controlled-fertility populations suggested no relationship or a negative relationship (Vining 1986; Pérusse 1993). However, more recent studies have demonstrated a positive relationship for men but not women in Western populations, largely due to higher rates of childlessness among poorer and lower-status men (Hopcroft 2006, 2015; Weeden et al. 2006; Barthold et al. 2012).

The research contributes to the literature on wealth and reproduction and to debates on men's productive and reproductive goals. We take a multivariate approach to these questions using empirical data from an indigenous Siberian community. The significance of this work links to understanding the effects of socioecological context on men's productive and reproductive goals. This study corroborates studies that have identified multiple pathways by which wealth affects male RS in foraging and horticultural societies, specifically hunting skill, material wealth, and support from kin (von Rueden et al. 2011, 2015; Wood and Marlowe 2013).

Recent studies on inequality in human society divide wealth into three classes - embodied, material, and relational - to better understand persistent inequality in different types of subsistence systems (Borgerhoff Mulder et al. 2009; Bowles et al. 2010). Following Bowles et al. (2010:9), we define wealth as "an attribute of the individual that contributes to a flow of valued goods or services," which then can be leveraged to increase RS, acknowledging that types of wealth pursued may vary across time and ecological circumstances (Shennan 2011). Embodied wealth is defined as somatic development, skills, and knowledge, specifically formal education and hunting skill in our case. Material wealth is defined as access to physical property and material goods, specifically access to hunting territories and critical hunting implements and transportation. Relational wealth (social capital) is defined as the number and quality of social relationships, specifically, in our case, numbers of individuals in four types of men's close relatives and a categorization of men's occupational networks (occupational tier). This article investigates how variation within these three wealth classes is related to the variability in men's RS in a monogamous community of majority indigenous people in the Siberian Arctic. We use these findings to explore the pathways by which wealth influences men's RS in this context.

Smith (2004) argues that the correlation between hunting success and RS in men may be accounted for by several proximate mechanisms. Smith discusses the evidence for each of these mechanisms in five well-documented societies and argues that widespread sharing of game meat within huntergatherer communities weakens the first three. There has been much debate within anthropology on the merits of direct provisioning versus indirect reciprocity and costly signaling (Hawkes 1993, 2010; Hill and Kaplan 1993; Gurven and Hill 2009, 2010; Wood and Marlowe 2013), largely hinging on the degree to which hunters control their results of production. 
The degree to which meat is controlled by producers and their families in foraging societies is variable, but even where sharing is widespread, producers often keep larger shares than are distributed to others and are able to direct portions to specific other individuals (Gurven 2004).

After examining the effects of a number of variables representing wealth on men's RS, we address the question of mechanism and producer control. In 2001 and 2003, J. P. Ziker documented 77 foraging excursions and subsequent distributions of the hunters' portions. An analysis of the 36 hunters' meat and fish distributions documented in two field seasons indicates a high level of producer priority over the catch. Producer priority is a prerequisite for the direct provisioning, dyadic reciprocity, and indirect reciprocity mechanisms by which hunting success influences male RS. We examine average interbirth intervals of the women with whom men had children, considering variable skill and the wealth of their male partners. The results are consistent with the mechanisms requiring producer priority.

\section{Methods}

The study community, Ust'-Avam, is situated on the Taimyr Peninsula in northern central Siberia. Two indigenous ethnic groups are represented in the community-the Dolgan and the Nganasan-along with a small minority of ethnic Russians, Ukrainians, and other former Soviet nationalities. The community is approximately $250 \mathrm{~km}$ by air from the regional capital, Dudinka, and $400 \mathrm{~km}$ by water from the large industrial city of Noril'sk. Transportation to and from the cities is expensive and limited (helicopter, barge, and snowmachine). As a result, the community depends in large part on hunting, fishing, and trapping activities for subsistence along with supplemental exchange with the larger market. Approximately $60 \%$ of caloric intake (and almost all of the protein) is derived from local subsistence activities (Ziker 2014). Ziker (2002) describes the increased importance of the local subsistence economy after the collapse of the Soviet planned economy. Ziker (2003) describes the development of post-Soviet communal property regimes.

J. P. Ziker spent approximately 36 months in the study community on a series of visits from 1994 through 2007. We operationalize the three wealth classes using a variety of data sets that J. P. Ziker developed in Siberia during the 1990s and 2000s. Community censuses, genealogical data, and specialized surveys and observations of hunters provide the data for the following analyses. Using Poisson regressions with Akaike information criterion (AIC) selection criteria and backwards stepwise Cox regressions, this report examines the effects of various forms of wealth on men's age-adjusted RS (survival of offspring to 5 years of age) and age at first birth to develop a more robust picture of contributions to male RS in a northern hunting and gathering community. In populations where infant mortality is high, survival to 5 years of age is used as a better proxy of RS than total number of children born. Data on the number of children were extracted from J. P. Ziker's 1997, 2003, and 2007 residential censuses and genealogies updated through 2007. Censuses were a complete list of households registered in the community. Finally, 77 foraging excursions were documented in the 2001 and 2003 field season with 36 hunters. These hunters participated in a specialized survey that collected information on the hunt locations, participants, amounts produced, subsequent distributions, and rationales for those distributions. With this snapshot, we examine producer control of output using descriptive statistics to validate ethnographic information on food sharing.

\section{Predictions regarding Wealth and Men's RS}

On the basis of this earlier research on the socioecology of food production (Ziker 2002; Ziker, Rasmussen, and Nolin 2016), we develop four specific predictions for the mechanisms by which wealth affects male RS.

Prediction 1: Men with Greater Numbers of Consanguineal Kin Will Have Greater Potential Sources of Nepotism and Cooperative Childrearing

Greater numbers of kin provide protective effects in many traditional societies. Network analysis of food distribution following 77 hunts in Ust'-Avam showed kinship as the statistically most significant predictor of interhousehold food sharing (Ziker, Rasmussen, and Nolin 2016). Controlling for kinship, the interaction between kinship and reciprocity also positively predicted food transfers. Previous analysis of food sharing at meals also showed kinship as the strongest predictor, with reciprocity between households increasing as kinship became closer (Ziker and Schnegg 2005). In food sharing at meals, this effect was in part due to clustering of highly related households for cooperative childcare.

\section{Prediction 2: Men with Higher Education Levels and Wage Labor Jobs Will Delay and Curtail Reproduction}

Following expectations from embodied capital theory (Lancaster and Kaplan 2010), men will delay reproduction to invest in their own education and careers, will invest in current offspring rather than add additional offspring, and will prefer smaller completed family sizes.

\section{Prediction 3: Hunting Skill Leads to Higher RS}

Increased hunting skill ratings reflect the ability and persistence of men in procuring food. The greater the food production, the more is available for investment in mating effort, spousal and offspring provisioning, risk-buffering with other producers, barter and trade outside the community for sup- 
plies and equipment used in hunting, and gifts to others within the community.

\section{Prediction 4: Greater Hunting Material Capital Leads to Higher RS}

Hunting material capital reflects the history of men's ability and persistence in procuring food. As above, the greater the food production, the more is available for investment in mating effort, spousal and offspring provisioning, riskbuffering with other producers, barter and trade outside the community for supplies and equipment used in hunting, and gifts to others within the community.

\section{Dependent Variables}

Descriptive statistics of all variables are presented in table A1 (tables A1-A5 available online). We use two dependent variables for this study. The first is the number of children surviving to 5 years of age. We use the number of children surviving to 5 years of age, rather than the total number of children born, to provide a better estimate of completed fertility, taking into consideration survivorship of the very young. The infant mortality rate in the community was 87:1,000 in 1996 (Ziker 2002:95), considerably higher than that for native Siberian peoples on average in the early 1990 s (Vishnevskii 1994:156) and four times higher than that in Russia on average at that time (United Nations 2013). The second dependent variable, age at first birth (AFB), is the age of a man at the time of the birth of his first child or, for right-censored cases, his age in 2007 (the latest census) if he had fathered no children by that time.

\section{Independent Variables}

Embodied wealth is a concept that represents past investment or experience and the resulting individual's capabilities. Rating interviews about men's hunting skill with nine key informants in 2003 provide ordinal data on a threepoint scale $(1=$ poor hunter, $2=$ good hunter, $3=$ excellent hunter) for 142 living men in the community. Not all informants provided ratings on all men, which is a problem discussed below. To represent level of education, we use the number of years of schooling each man completed as recorded in the village administration census of 2002 and updated with subsequent interviews in 2007.

Material wealth includes assets, income, or other forms of material resources. We operationalize material wealth related to hunting using a scale consisting of data on four types of equipment ascertained in key interviews in 2003 and rights to hunting land holdings in 2003 and 2007, as recognized in the community registry. Minimal equipment is required for some forms of food production in Ust'-Avam. Snares can be established with a minimal amount of wire, and fishing can be done with a hook and line. Not everyone in the community owns a rifle, snowmobile, or boat motor. Our material wealth scale represents the variation for the most committed hunters. We also examine employment and wage labor listed in 2003 and 2007 community registries as a dummy variable representing material wealth in the competitive labor market.

Relational wealth is each individual's network of social relations. Often thought of as social and political capital, relational wealth is becoming increasingly important in the analyses of human behavior, because it structures constraints and opportunities for individuals (Sear and Mace 2008; Borgerhoff Mulder et al. 2009; Bowles et al. 2010). We operationalize relational wealth using counts of kin, specifically the number of living siblings, parents, parents' siblings, and parents' siblings' offspring. Also, we use men's historical occupational tier (staff hunter, brigade hunter, amateur, helper, or nonhunter) in 2003 to operationalize the social relations in which the hunter is embedded in the realm of work. These tiers reflect levels of participation in the Gospromkhoz Taimyrski (government hunting enterprise), with staff hunters being the most integrated. Staff hunters were listed in the community registry. Classification of other men's occupational tier was conducted on the basis of expert interviews in 2003 and 2007.

\section{Scale Reliability}

\section{Hunter Skill Evaluations (Embodied Wealth)}

A Cronbach's alpha statistic of 0.825 indicates high interrater reliability of five of the nine evaluators. These five provided evaluations of 56 men in common. Not all evaluators provided ratings on all men, so we use this subsample as a control against a longer list of men with fewer evaluations. For missing evaluations, we calculated the mean rating that an evaluator provided for the men evaluated, and we imputed that mean for the remaining men not rated by that evaluator. This allows us to use all the ratings provided by all nine evaluators and to calculate ratings for those men that were rated by fewer evaluators. This expands the data set of rated men from 56 to 142 men. In the larger data set, there are 1,278 total evaluations of which 494 are imputed. A second Cronbach's alpha statistic of 0.724 indicates the interrater reliability remains good. Analysis of the hunter skill ratings of the subsample of 56 men resulted in higher coefficients in the Poisson regressions on men's RS and Cox regressions of age at first birth compared with the set of 142 ratings (tables A2, A3). This indicates possible downward bias in coefficient estimates due to the measurement error introduced by imputation in the larger sample of 142 men employed below. Furthermore, because of high annual variation in hunting returns documented among huntergatherers, Hill and Kintigh (2009) suggest that evaluations of men's hunting skill by other community members may be 
more reliable than observed hunting returns from a single field season.

\section{Hunter Wealth (Material)}

Four types of equipment are inventoried in J. P. Ziker's 2003 interviews: (1) snowmobile, (2) boat motor, (3) rifle, and (4) shotgun. These capital equipment items, plus a dummy variable representing (5) occupation of hunting territories, were evaluated using the mokken package (van der Ark 2013) in $\mathrm{R}$, version 3.0.0 ( $\mathrm{R}$ Core Team 2013). Mokken scaling (Mokken 1971) is a probabilistic, nonparametric method of unidimensional scale construction similar to Guttman scaling. The resulting hunter material wealth scale ( 0 to 5$)$ has a Lovinger's $\mathrm{H}=0.672(P=.048)$, indicating strong scalability of these five items (Lovinger 1948). Wage labor from the 2007 census is analyzed separately, because it is not correlated to hunting assets in Ust'-Avam (biserial correlation coefficient $\left.r_{\mathrm{b}}=0.049 ; P=.42\right)$.

\section{Results: Variables Individually Entered}

We examine the number of men's offspring surviving to 5 years of age (male RS) and AFB entering independent variables separately in Poisson and Cox regressions (respectively) to determine which independent variables are candidates for multiple regression models. Poisson regressions on RS were performed in R ( $\mathrm{R}$ Core Team 2013). Cox's proportional hazards regressions of AFB were performed in IBM SPSS, version 20.0.0 (IBM 2011). Because of nonindependence of cases, we use a bootstrap procedure to estimate robust standard errors. The results for Poisson regressions of men's RS, controlling for age, are provided in table 1, and results for AFB are provided in table 2. We control for age in the Poisson regressions by entering risk-years and risk-years squared into each regression. Risk-years is the number of years after 15 years of age. We set
15 years of age as a cutoff point because that was the age of the youngest father in the data set.

\section{Poisson Regressions}

Of the two embodied wealth variables, hunter skill ratings are highly significant and moderate predictors of men's RS, adjusted for age, whereas level of education is a virtually flat and statistically insignificant predictor. Education may have this relationship for two reasons: (1) little variation in educational level for men who finished schooling during the existence of the Soviet Union, particularly for those men born during the 1950s through the 1980s; (2) completion of high school education is not a prerequisite to learning the skills necessary for hunting, and it may in fact detract from those skills (UNESCO 2009; Reyes-Garcia et al. 2010). The material wealth scale is also a highly significant predictor of ageadjusted RS, whereas a wage labor dummy variable was poorly predictive and insignificant. Occupational tier is a significant positive predictor of men's RS, and only one of the four categories of kin, full first cousins, is a statistically significant negative predictor of men's RS.

A one-unit increase in hunter skill results in $\exp (0.088)=$ 1.09 times the number of children predicted by age alone (table 1). The material wealth scale result indicates a one-unit increase in wealth results in $\exp (0.143)=1.15$ times the number of children predicted for their age. Occupational tier has a similar effect, with a one-unit increase increasing the number of children $\exp (0.162)=1.18$ times. The number of first full cousins reduces the expected number of children by $5.9 \%$ (exp $(-0.61))$ with every additional cousin.

\section{Cox Regressions}

In predicting $\mathrm{AFB}$, the hunter skill evaluations and level of education are both significant embodied wealth variables

Table 1. Poisson regression of mens' reproductive success on wealth covariates

\begin{tabular}{lccccc}
\hline Individual covariate & No. of subjects & Unstandardized coefficient & SE & $z$-value & $P$ \\
\hline Embodied wealth: & & & & & \\
$\quad$ Hunter skill rating & 142 & .088 & .025 & 3.568 & $.000^{* * *}$ \\
$\quad$ Education & 240 & .039 & .037 & 1.072 & .284 \\
Material wealth: & & & & & \\
$\quad$ Hunter wealth scale & 272 & .143 & .035 & 4.034 & $.000^{* * *}$ \\
$\quad$ Wage labor (dummy) & 272 & .210 & .154 & 1.362 & .173 \\
Relational wealth: & & & & & \\
$\quad$ No. of living siblings & 272 & .004 & .041 & .107 & .915 \\
No. of parents & 272 & -.062 & .150 & -.415 & .678 \\
No. of parents' siblings & 272 & -.061 & .089 & -1.545 & .122 \\
No. of full first cousins & 272 & .162 & .021 & -2.951 & $.003^{* *}$ \\
Occupational tier & 272 & .039 & 4.136 & $.000^{* * *}$ \\
\hline
\end{tabular}

Note. Risk-years (years since age 15 years) and risk-years ${ }^{2}$ are entered with each covariate to control for age. $Z$-test of significance. $\mathrm{SE}=$ standard error.

${ }^{* *} P<.01$.

*** $P<.001$. 
Table 2. Cox regression of the hazard of a man's first child's birth (15 years of age or older)

\begin{tabular}{lccccc}
\hline Individual covariate & No. of subjects & $\beta$ & SE & $\operatorname{Exp}(\beta)$ & $P$ \\
\hline Embodied wealth: & & & & & \\
$\quad$ Hunter skill rating & 142 & .088 & .036 & 1.091 & $.010^{* *}$ \\
$\quad$ Education & 240 & .101 & .050 & 1.106 & $.024^{*}$ \\
Material wealth: & & & & & \\
$\quad$ Hunter wealth scale & 272 & .138 & .048 & 1.148 & $.005^{* *}$ \\
$\quad$ Wage labor (dummy) & 272 & .548 & .223 & 1.731 & $.016^{*}$ \\
Relational wealth: & & & & & .082 \\
$\quad$ No. of living siblings & 272 & -.089 & .053 & .915 & .065 \\
$\quad$ No. of parents & 272 & .059 & .150 & 1.061 & .670 \\
$\quad$ No. of parents' siblings & 272 & -.027 & .081 & .973 & .706 \\
$\quad$ No. of full first cousins & 272 & -.023 & .021 & .977 & .237 \\
$\quad$ Occupational tier & 272 & .139 & .058 & 1.150 & $.017^{*}$ \\
\hline
\end{tabular}

Note. Robust bootstrapped standard errors, 2-tailed significance.

${ }^{*} P<.05$.

** $P<.01$.

(table 2). A unit increase in hunter skill increases the hazard of having a first child by 1.091. A year increase in education increases the hazard of having a first child by 1.106. Of material wealth variables, the wealth scale and wage labor participation variables were both significant predictors of AFB. A unit increase in material wealth increases the hazard of having a first child by 1.148. Participation in wage labor increases the hazard by 1.731 . The only significant relational wealth variable is occupational tier, which increases the hazard of having a first child by 1.150 . When entered individually, our kin-based relational wealth measures are not significant predictors of AFB.

Figure 1 illustrates the effect of hunter skill on age at first birth and the proportion of men who have had a child. The figure divides men into three groups by hunter skill evaluation: those within one standard deviation of average evaluation, and those greater or less than one standard deviation from average evaluation. Most of the men in the group with the highest scores are fathers by 35 years of age, whereas roughly $60 \%$ of men in the middle category and $50 \%$ of men in the lowest category are fathers by this age.

\section{Results: Best-Reduced Models}

We ran all possible subsets of independent variables in Poisson regressions on male RS and identified the best-fitting model by AIC. We similarly entered the full set of variables in a backwards-stepwise Cox regression to identify the bestreduced model of men's age at first birth.

\section{Male RS}

Three wealth variables remain in the final model of men's RS: hunter material wealth, number of parent's siblings, and number of full first cousins (table 3 ). The best-reduced model explains $6.4 \%$ of the variance in men's RS (McFadden Pseudo- $R^{2}=.064$ ) beyond that explained by age (risk-years and risk-years squared) alone; together with these age controls, the model explains $40.8 \%$. Hunter skill ratings, education, wage labor (dummy), occupational tier, men's parents, and number of siblings all dropped out of the best-reduced model. Independent of age, the final model shows the importance of relational wealth and material wealth related to hunting in explaining variance in male RS. The number of a man's parent's siblings have a significant positive effect, whereas first cousins have a weaker and negative effect. Although this seems like a small amount of variance explained by wealth factors, a few points should be taken into consideration. This study occurred over a very volatile time period with drastic economic changes and corresponding effects on fertility. These changes are likely introducing temporal effects disrupting the relationship between wealth and RS over this period and introducing additional variance. In addition, the hunter skill rating and material wealth measures are snap-

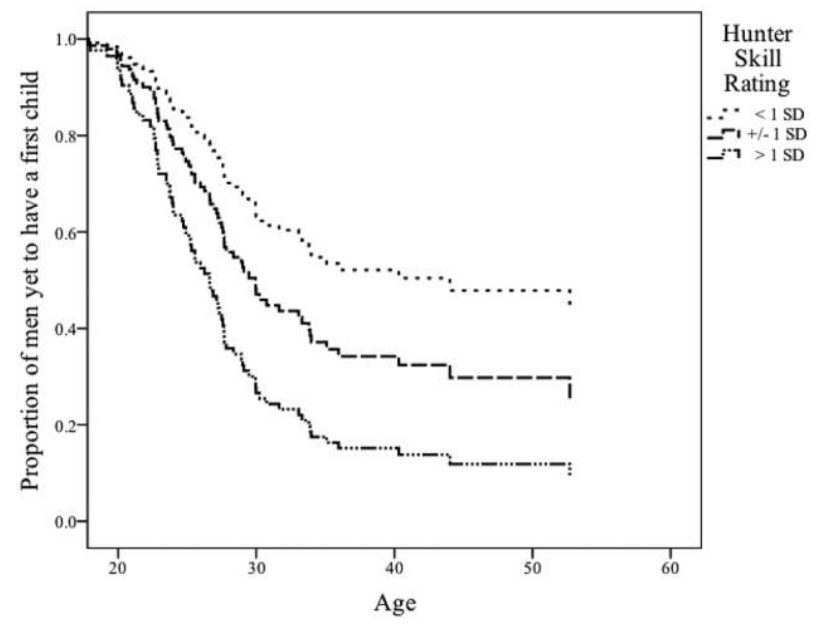

Figure 1. Survival function for men's age in years at first birth by hunter skill rating. $\mathrm{SD}=$ standard deviation. 
Table 3. Poisson regression best-reduced model for mens' reproductive success

\begin{tabular}{lrrrc}
\hline Covariate & Estimate & SE & $z$-value & $P$ \\
\hline (Intercept) & -3.539 & .616 & -5.741 & $.000^{\star * *}$ \\
Risk years & .185 & .033 & 5.679 & $.000^{\star * *}$ \\
Risk years ${ }^{2}$ & -.002 & .000 & -4.503 & $.000^{\star * *}$ \\
Hunter wealth scale & .179 & .043 & 4.168 & $.000^{\star * *}$ \\
No. of parents' siblings & .318 & .143 & 2.221 & $.026^{\star *}$ \\
No. of full first cousins & -.112 & .333 & -3.361 & $.001^{\star * \star}$ \\
\hline
\end{tabular}

Note. The $\chi^{2}$ value for the model is 29.725; degrees of freedom (df): 3 , $P=1.577 \mathrm{e}-06, \mathrm{McF}$ adden Pseudo- $R^{2}=0.064$ against a risk-years (years since age 15 years) and risk-years ${ }^{2}$ null model; McFadden Pseudo- $R^{2}=$ 0.408 against intercept-only null model. $Z$-test of significance.

** $P<.01$.

$\star * * P<.001$.

shots in 2003, and their effects are likely downward-biased as a result of measurement error. The fact that a significant portion of the variance in male RS is explained with these wealth measures points to significant underlying effects. To the extent that these forms of wealth are transmittable across generations, significant inequalities may be maintained.

\section{Age at First Birth}

In the best-reduced Cox regression of AFB, hunter material wealth, wage labor (dummy), parents' siblings, and full first cousins are significant predictors of the hazard of having a first child (table 4). Hunter skill evaluations and occupational tier drop out of the regression. Hunter skill evaluations, hunter material wealth, and occupational tier are correlated but are not multicollinear (VIF collinearity statistics for all three variables regressed on age-adjusted RS are $<2$ ). The number of parents' siblings and first cousins also affect age at first birth, but in opposite directions, as in the male RS results.

Variables representing hunters' material and relational wealth most strongly account for men's RS inequality in this analysis. Embodied wealth (hunting skill) appears to be an important variable but falls out of both final models. The influence of participation in the competitive labor market on men's RS goes in the opposite direction as predicted. Wage labor participation lowers AFB.

\section{Discussion}

Relational wealth measures are important predictors of male RS in Ust'-Avam. Occupational tier individually predicts both age-adjusted RS and age at first birth but is not retained in either best-reduced models. Occupational tier is correlated with both hunting skill and hunter wealth scales. Of the remaining relational wealth measures, two kinship variables have countervailing effects on men's RS, providing only partial support for prediction 1: aunts and uncles have a positive effect on men's RS; and the number of full first cousins lowers men's RS and AFB. This result corroborates ethnographic evidence of allocare in the community (Ziker 2002; Ziker and Schnegg 2005). It appears that aunts and uncles provide allocare, but this effect is reduced when they have children of their own. This result may reflect the mixed effects of alloparental effort on one hand and resource competition on the other.

We find little evidence for human capital delays in Ust'Avam (prediction 2). Both wage-labor employment in the community and education level individually reduced a man's time to first birth, and wage-labor employment was retained in the full Cox regression model. This may be due to the fact that many men were educated during the Soviet period, when the expectations of well-paying jobs were higher. We would not necessarily expect this relationship between human capital and earlier AFB to hold in the future.

Consistent with prediction 3, hunter skill rating individually predicted men's RS and AFB. However, this variable is not retained in the final models. Because the effect of hunter skill rating is downward biased due to the imputation of missing ratings, this variable is likely to be more important than our final models indicate.

Material wealth has a positive effect on men's reproduction, consistent with prediction 4. Survival analysis indicates that men who scored higher on hunting wealth had their first child when they were younger. In addition, controlling for age, men with greater hunting material wealth had more offspring than men with less hunting wealth in Poisson regressions. This variable is retained in both the Poisson and Cox final models. These two sets of findings provide evidence that variation in material wealth is associated with men's RS in this monogamous foraging/mixed-economy community.

\section{Proximate Mechanisms of Increased RS: Interbirth Interval, Foraging Productivity, and Producer Control}

These findings are relevant to broader questions about the mechanisms by which variation in embodied, material, and relational wealth influences men's RS. There has been much debate in anthropology about the importance of men's direct provisioning of wives and children versus other possible benefits for men's hunting activities (Hawkes and Bliege Bird 2002; Hawkes et al. 2010; Hill and Gurven 2009, 2010; Wood and Marlowe 2013). In Ust'-Avam, ethnographic observations and demographic data on men's mating strategies are not consistent with costly signaling. Young women leave the village to pursue career opportunities in greater numbers than men, resulting in a male-biased sex ratio (111:100 in 2003 and 104:100 in 2007) that reduces men's mating opportunities. A recent study by Schacht and Borgerhoff Mulder (2015) shows that, where adult sex ratio is male biased, indices of within-pair commitment are also increased. Men may be signaling to attract a first spouse, but in a context where the 
Table 4. Backwards stepwise cox regression for men's age at first child's birth

\begin{tabular}{lccccc}
\hline Covariates & No. of subjects & $\beta$ & SE & $\operatorname{Exp}(\beta)$ & $P$ \\
\hline Hunter wealth scale & 272 & .155 & .057 & 1.168 & $.002^{* *}$ \\
Wage labor (dummy) & 272 & .592 & .213 & 1.808 & $.004^{* *}$ \\
No. of parents' siblings & 272 & .233 & .105 & 1.262 & $.015^{*}$ \\
No. of full first cousins & 272 & -.065 & .030 & .937 & $.017^{*}$ \\
\hline
\end{tabular}

Note. Omnibus test $-2 \log$ likelihood $=1,054.038 ; \chi 2$ test $=19.478$, degrees of freedom $=4 ; P<.01$. Robust bootstrapped standard errors. $P$ values determined by 2 -tailed test.

${ }^{*} P<.05$.

** $P<.01$

population is highly monogamous, we can discount signaling as a mechanism for attracting additional concurrent mates. In fact, in Ust'-Avam, fewer men than women have children in second marriages. In our sample of 272 men, 144 were unmarried, 115 had been married once, and only 13 (5\% of all men or $10 \%$ of ever-married men) were married a second time. This remarriage rate is significantly lower than that in the United States.

If men are not are not leveraging their wealth to increase their reproduction through multiple concurrent mates, then what accounts for the relationship between wealth and fertility? To more closely examine the mechanisms producing higher male RS, we compared the average interbirth intervals (IBIs) of the wives of men in the sample (mean IBI $\pm \mathrm{SD}$, $3.7 \pm 2.2, n=81$; fig. 2). Student $t$-tests (one-tailed, independent samples) indicate that the wives of men with high hunter skill rating and material wealth have significantly shorter IBIs than those men with lower skill rating and material wealth. Although this is consistent with direct provisioning, we do not have direct measures of women's productivity and cannot address the alternative hypothesis that this effect on IBI is due to positive marital assortment of better hunters and more productive women.

In addition, hunters show strong producer control. Of the total amount of meat and fish available from the 77 hunts documented in 2001 and 2003, the mean ( \pm SD) proportion of the catch remaining with the hunter or his family is $45.4 \% \pm 35.3 \%$. The mean proportion $( \pm \mathrm{SD})$ sold or bartered for supplies - usually with outsiders or the successor to the government hunting enterprise-is $26 \% \pm 39.0 \%$, and the amount given as voluntary transfers is $19 \% \pm 23.7 \%$. These first three kinds of distribution represent producer control (Ziker 2006, 2007). The mean proportion ( \pm SD) given in exchange for other goods or services within the community is $5.2 \% \pm 1.0 \%$, and the mean amount requested of the hunter is $4.3 \% \pm 13.1 \%$. Eleven of 36 hunters kept $100 \%$ of the catch under their control. We did not find that child burden correlated with hunting effort in the sample of 77 hunts (tables A4, A5), suggesting that the correlation between RS and hunting skill is not simply due to men with more children hunting more.

In high-latitude ecologies, like those of Ust'-Avam, men typically play a crucial role in the energetics of reproduction, because gathering of plant foods is highly seasonal and limited calorically (Kaplan et al. 2000). Men generate by far the vast majority of the volume of locally procured food in Ust'-Avam, and these foods have both caloric and cultural significance. We identify three effects of success at hunting as measured by our wealth indices (hunter material wealth
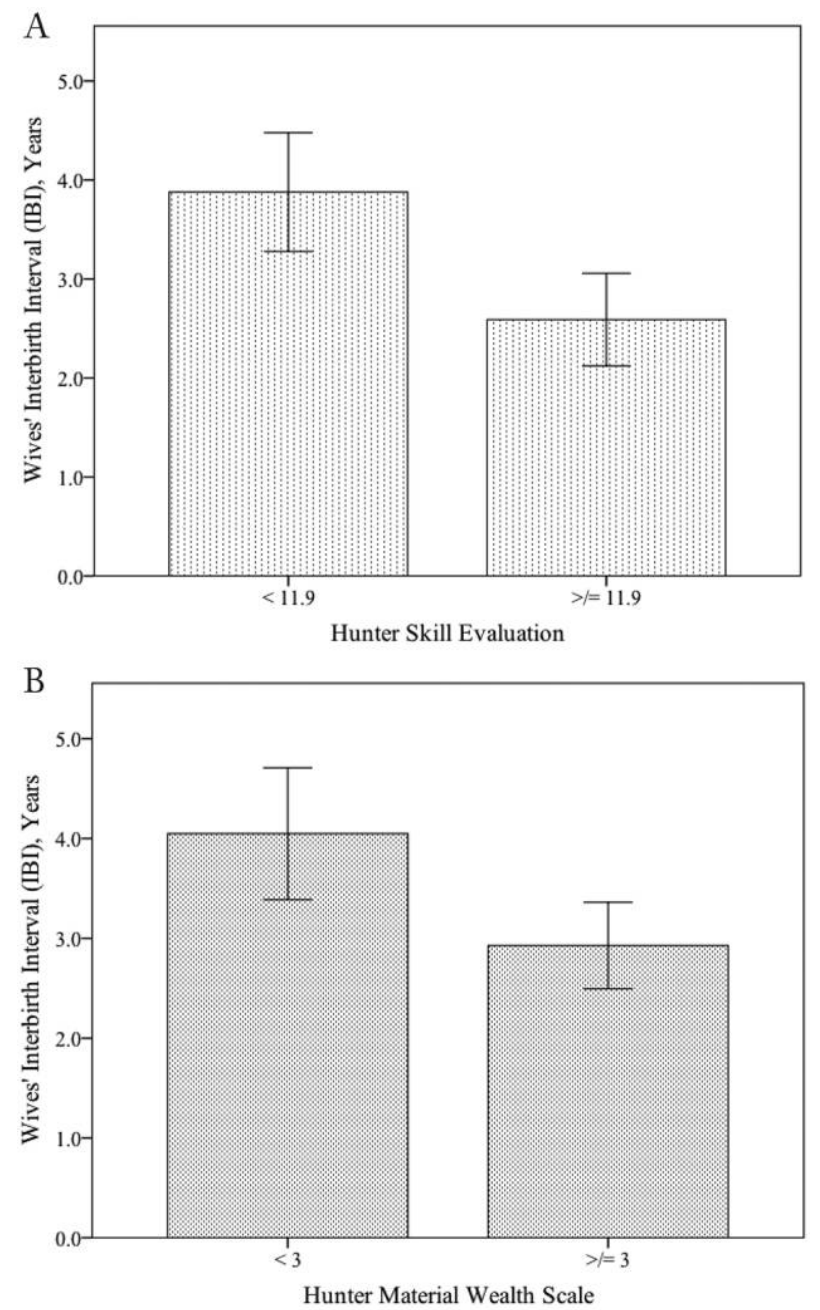

Figure 2. Average interbirth interval (IBI) of men's wives by hunter skill rating $(A)$ and hunter material wealth scale $(B)$. The $t$-test significance is a $P$ value of $<.05$, one-tailed, for hunter skill and $<.01$, one-tailed, for material wealth. 
and hunter skill): earlier AFB establishing reproductive careers; shorter average IBI of wives; and greater RS. Participation in wage labor predicts earlier AFB but not the other two effects. Thus, wage labor participation partly contradicts expectations of embodied capital theory and partly confirms them. Considering the male-biased adult sex ratio and high degrees of monogamy, it is likely that female choice of husband is strong in Ust'-Avam. Women's choice likely considers a variety of indicators of success. Hunting ability is the most robust, but wage labor participants appear to be attractive at least in terms of earlier AFB. The importance of hunting skill and hunting material wealth is consistent with ethnographic observations of the development of hunters and female choice. Many young boys become involved in fishing and using snares, and community members are keen to discuss the interest and time boys spend in the tundra. People pick up on men's hunting skill early on, and not all descendants inherit primary rights to hunting territories. Hunters retain control of their catch, and they deliver it to their wives (or parents) for processing and distribution. The wives of better hunters are thus relatively well provisioned and, as a result, have shorter IBIs, resulting in higher RS for themselves and their husbands. The relationship between hunting success and RS in Ust'-Avam appears more consistent with a female choice/provisioning model than a signaling-formates model.

\section{Acknowledgments}

This research would not have been possible without the hospitality, good will, and cooperation of the people of the study community in the Taimyr Region. Funding for this research was provided by the Leakey Foundation (2001), the Max Planck Institute for Social Anthropology (2003), and the National Science Foundation (OPP 0631970). We thank Sioban Mattison, Christopher von Rueden, and an anonymous reviewer for comments on the manuscript. All conclusions are our own.

\section{References Cited}

Barthold, Julia A., Mikko Myrskylä, and Owen R. Jones. 2012. Childlessness drives the sex difference in the association between income and reproductive success of modern Europeans. Evolution and Human Behavior 33 (6):628-638.

Betzig, Laura. 1997. Roman polygyny. In Human nature: a critical reader. Laura Betzig, ed. Pp. 375-398. New York: Oxford University Press.

Borgerhoff Mulder, Monique, and Brett A. Beheim. 2011. Understanding the nature of wealth and its effects on human fitness. Philosophical Transactions of the Roval Society B: Biological Sciences 366:344-356.

Borgerhoff Mulder, Monique, Samuel Bowles, Tom Hertz, Adrian Bell, Jan Beise, Greg Clark, Ila Fazzio, et al. 2009. Intergenerational wealth transmission and the dynamics of inequality in small-scale societies. Science 326(5953):682-688.

Bowles, Samuel, Eric Alden Smith, and Monique Borgerhoff Mulder. 2010. The emergence and persistence of inequality in premodern societies: in troduction to the special section. Current Anthropology 51(1):7-17.

Chagnon, Napoleon. 1979. Is reproductive success equal in egalitarian societies? In Evolutionary biology and human social behavior: an anthro- pological perspective. Napoleon Chagnon and William Irons, eds. Pp. 374401. North Scituate, MA: Duxbury.

. 1988. Life histories, blood revenge, and warfare in a tribal population. Science 239(4843):985-992.

Gurven, Michael. 2004. To give and to give not: the behavioral ecology of human food transfers. Behavioral and Brain Sciences 27(4):543-559.

Gurven, Michael, and Kim Hill. 2009. Why do men hunt? a reevaluation of "Man the Hunter" and the sexual division of labor. Current Anthropology 50(1):51-74.

2010. Moving beyond stereotypes of men's foraging goals: reply to Hawkes, O'Connell, and Coxworth. Current Anthropology 51(2):265-267.

Hawkes, Kristen. 1993. On why male foragers hunt and share food: reply to Hill and Kaplan. Current Anthropology 34(5):706-710.

Hawkes, Kristen, and Rebecca Bliege Bird. 2002. Showing off, handicap signaling, and the evolution of men's work. Evolutionary Anthropology 11 (2):58-67.

Hawkes, Kristen, James F. O'Connell, and James E. Coxworth. 2010. Family provisioning is not the only reason men hunt: a comment on Gurven and Hill. Current Anthropology 51(2):259-264.

Hill, Kim, and A. Magdelena Hurtado. 1996. Ache life history: the ecology and demography of a foraging people. Chicago: Aldine de Gruyter.

Hill, Kim, and Hillard Kaplan. 1993. On why male foragers hunt and share food. Current Anthropology 34(5):701-710.

Hill, Kim, and Keith Kintigh. 2009. Can anthropologists distinguish good and poor hunters? implications for hunting hypotheses, sharing conventions, and cultural transmission. Current Anthropology 50(3):369-378.

Hopcroft, Rosemary L. 2006. Sex, status, and reproductive success in the contemporary United States. Evolution and Human Behavior 27(2):104120 .

2015. Sex differences in the relationship between status and number of offspring in the contemporary U.S. Evolution and Human Behavior 36 (2):146-151

IBM. 2011. IBM SPSS statistics for Windows, version 20.0. Armonk, NY: IBM. Irons, William. 1979. Cultural and biological success. In Evolutionary biology and human social behavior: an anthropological perspective. Napoleon Chagnon and William Irons, eds. Pp. 257-272. North Scituate, MA: Duxbury.

Kaplan, Hillard, Kim Hill, Jane Lancaster, and A. Magdelena Hurtado. 2000. A theory of human life history evolution: diet, intelligence, and longevity. Evolutionary Anthropology 9(4):156-185.

Lancaster, Jane B., and Hillard S. Kaplan. 2010. Embodied capital and extrasomatic wealth in human evolution and human history. In Human Evolutionary Biology. Michael P. Muehlenbein, ed. Pp. 439-455. Cambridge: Cambridge University Press.

Loevinger, Jane. 1948. The technic of homogeneous tests compared with some aspects of "scale analysis" and factor analysis. Psychological Bulletin 45(6):507-529.

Mokken, R. 1971. A theory and procedure of scale analysis. New York: de Gruyter.

Nettle, Daniel, and Thomas V. Pollet. 2008. Natural selection on male wealth in humans. American Naturalist 172(5):658-666.

Pérusse, Daniel. 1993. Cultural and reproductive success in industrial societies: testing the relationship at the proximate and ultimate levels. Behavioral and Brain Sciences 16(2):267-322.

$\mathrm{R}$ Core Team. 2013. R: a language and environment for statistical computing. R Foundation for Statistical Computing, Vienna. http://www.R-project.org/.

Reyes-García, Victoria, Eric Kightley, Isabel Ruiz-Mallén, Nuria FuentesPeláez, Katie Demps, Tomás Huanca, and Maria Ruth MartínezRodríguez. 2010. Schooling and local environmental knowledge: do they complement or substitute each other? International Journal of Educational Development 30(3):305-313.

Schacht, Ryan, and Monique Borgerhoff Mulder. 2015. Sex ratio effects on reproductive strategies in humans. Royal Society Open Science. doi: $10.1098 /$ rsos. 140402 .

Sear, Rebecca, and Ruth Mace. 2008. Who keeps children alive? a review of the effects of kin on child survival. Evolution and Human Behavior 29 (1):1-18.

Shennan, Stephen. 2011. Property and wealth inequality as cultural niche construction. Philosophical Transactions of the Roval Society B: Biological Sciences 366:918-926.

Smith, Eric Alden. 2004. Why do good hunters have higher reproductive success? Human Nature 15(4):343-364.

United Nations. 2013. World population prospects: the 2012 revision. http:// esa.un.org/unpd/wpp/Excel-Data/mortality.htm. 
United Nations Educational, Cultural, and Scientific Organization (UNESCO). 2009. Learning and knowledge in indigenous societies today. Paris: UNESCO. van der Ark, L. A. 2013. mokken: Mokken scale analysis in R. R package, version 2.7.5. https://sites.google.com/a/tilburguniversity.edu/avdrark/mokken.

Vining, Daniel R. 1986. Social versus reproductive success: the central theoretical problem of sociobiology. Behavioral and Brain Sciences 9(1):167-216.

Vishnevskii, A. G., ed. 1994. Naselenie Rossii 1994: Vtoroi Ezhegodnyi Demograficheskii Doklad. Moskva: Institut Narodnokhoziaistvennogo Prognozirovaniia RAN.

von Rueden, Christopher, Michael Gurven, and Hillard Kaplan. 2011. Why do men seek status? fitness payoffs to dominance and prestige. Proceedings of the Royal Society B: Biological Sciences 278(1807):2223-2232.

von Rueden, Christopher, Michael Gurven, Hillard Kaplan, and Jonathan Stieglitz. 2015. Leadership in an egalitarian society. Human Nature 25 (4):538-566.

Weeden, Jason, Michael J. Abrams, Melanie C. Green, and John Sabini. 2006 Do high-status people really have fewer children? education, income, and fertility in the contemporary U.S. Human Nature 17(4):377-392.

Wood, Brian M., and Frank W. Marlowe. 2013. Household and kin provisioning by Hadza men. Human Nature 24(3):280-317.
Ziker, John P. 2002. Peoples of the tundra: northern Siberians in the postcommunist transition. Prospect Heights, IL: Waveland.

. 2003. Assigned territories, family/clan/communal holdings, and common-pool resources in the Taimyr Autonomous Region, northern Russia. Human Ecology 31(3):331-368.

- 2006. The social movement of meat in Taimyr, northern Russia. Nomadic Peoples 10(2):105-133.

2007. Subsistence and food sharing in northern Siberia. Ecology of Food and Nutrition 46:445-467.

- 2014. Subsistence and sharing in northern Siberia: experimental economics with the Dolgan and the Nganasan. In Experimenting with social norms: fairness and punishment in cross-cultural perspective. Jean Ensminger and Joseph Henrich, eds. Pp. 337-356. New York: Russell Sage Foundation.

Ziker, John P., Joellie Rasmussen, and David A. Nolin. 2016. Indigenous Siberians solve collective action problems through sharing and traditional knowledge. Sustainability Science 11(1):45-55.

Ziker, John, and Michael Schnegg. 2005. Food sharing at meals: kinship, reciprocity, and clustering in the Taimyr Autonomous Okrug, northern Russia. Human Nature 16(2):178-210.

This content downloaded from 132.178.155.125 on May 19, 2016 10:41:49 AM 